\title{
Comparison of face-to-face and telephone consultations in primary care: qualitative analysis
}

\author{
Heather Hewitt, Joseph Gafaranga and Brian McKinstry
}

\begin{abstract}
Background

There is evidence that telephone consultations in general practice are typically shorter than face-to-face consultations and that fewer problems are presented in them.

Aim

To compare the communicative practices of doctors and patients in face-to-face and telephone consultations, in order to understand the contrasts between the two consulting modes.

Design of study

Conversation analysis.

Setting

Eight NHS GP surgeries in Scotland.
\end{abstract}

Method

Transcription and conversation analysis of 32 face-to-face and 33 telephone consultations.

Participants

Eighteen GPs and 65 patients.

Results

There are no underlying contrasts between the communicative practices used in face-to-face and telephone consultations. Telephone consultations are typically used by patients to deal with a limited range of single-issue concerns, whereas a wide range of different problem types is dealt with in face-to-face consultations. Most telephone consultations for new problems lead to a face-to-face meeting rather than a diagnosis, making them shorter than equivalent face-to-face consultations. Interaction in telephone consultations is continuous and orderly, but in face-to-face consultations there are periods of silence that facilitate the introduction of additional topics, including social speech and rapport building. Doctors on the telephone are less likely to elicit additional concerns than in face-to-face consultations, and ask fewer questions when patients present self-diagnosed problems or describe problems with treatment.

Conclusion

Doctors in general practice do not substantially change their communicative behaviour on the telephone.

Telephone consultations are shorter and include less problem disclosure than face-to-face meetings, partly because they are typically mono-topical and partly because of intrinsic differences between the two channels.

Keywords

communication; consultation; qualitative analysis; telephone.

\section{INTRODUCTION}

There is growing emphasis on improving patient access to primary care services, and increased use of telephone consulting has been seen as one means of achieving this. ${ }^{1-3}$ While use of the telephone to deal with some types of problem appears to be effective, ${ }^{4,5}$ concerns remain about the overall quality and safety of the telephone as a consulting medium. ${ }^{6}$ In a recent comparative study of face-to-face and telephone consulting in general practice, the Roter interaction analysis system (RIAS) ${ }^{7}$ was used to explore the contrasts between the two consulting modes and it was found that telephone consultations were typically shorter than face-to-face meetings, and included less disclosure by patients, less questioning by doctors, and less discussion of problems. $^{8}$ Although the RIAS analysis revealed that there were contrasts between consultations in face-to-face and telephone channels, it did not shed any light on how or why they were present. To remedy this, a further indepth analysis was carried out using conversation analysis, a methodology increasingly adopted to

H Hewitt, PhD, research fellow, Centre for Population Health Sciences: General Practice Section; J Gafaranga, PhD, senior lecturer, School of Philosophy, Psychology and Language Sciences; B McKinstry, MD, FRCGP, reader, Centre for Population Health Sciences: General Practice Section, University of Edinburgh, Edinburgh.

Address for correspondence

Heather Hewitt, Centre for Population, Health Sciences: General Practice Section, University of Edinburgh, Doorway 3, Medical School, Teviot Place, Edinburgh, EH8 9AG. E-mail: Heather.Hewitt@ed.ac.uk

Submitted: 27 October 2009; Editor's response: 6 January 2010; final acceptance: 28 January 2010.

(C)British Journal of General Practice

This is the full-length article of an abridged version published in print. Cite this article as: Br J Gen Pract 2010; DOI: 10.3399/bjgp10X501831. 
improve understanding of medical communication,,$^{9,10}$ to examine the communicative practices underlying the differences between the face-to-face and telephone consultations in the data set. Since the main concern was the quality and safety of telephone consulting, the researchers wished to find out whether doctors consulting over the telephone were either limiting opportunities for problem disclosure or reducing quality and safety by diminishing attention to patients' concerns. To determine whether or not this was the case, four aspects of communicative practice were investigated:

- the opportunities provided for problem disclosure by patients;

- the methods used by doctors to obtain additional information about problems;

- the attention given by doctors to providing followup of problems; and

- the methods used by doctors and patients to close discussion of topics.

\section{METHOD}

Data

The data for the initial study consisted of audiorecordings of $18 \mathrm{GPs}$ in eight medical practices and patients attending the surgery or who were

\section{How this fits in}

Increased use of telephone consulting has the potential to help meet service demand and complement existing modes of patient care, but there are continuing concerns about quality and safety. Although substantial work has been carried out on the impact of telephone consulting and attitudes to it, little was hitherto known about the communicative practices of doctors and patients in telephone consultations or how they compare with those used in face-to-face meetings. This comparative analysis of the communicative practices used to complete similar actions in both consulting channels is the first of its kind for general practice consulting. It suggests that telephone consultations are typically treated by both doctors and patients as an appropriate medium for discussion of single non-complex concerns, but casts doubt on the suitability of the telephone for discussion of new acute problems, since they are almost always referred on for discussion face-to-face. The study analysis gives reassurance that doctors provide patients with similar levels of opportunity to present and discuss new acute problems over the telephone but raises questions about levels of attention when patients call to discuss self-diagnosed conditions or treatment concerns.

phoning in for telephone advice were sequentially recruited, through either arranged appointments or call-back. In the case of call-back, some patients were told that the doctor would phone them back between defined times, while others were called back immediately. Patients were asked to give verbal permission for recording of their consultation and

\section{Box 1. Transcription conventions.}

(The names of all participants have been changed)

D: doctor

P: patient

? rising intonation

a stop indicates the micro-interval between segments of speech

(.) a stop in round brackets indicates a pause of less than one second

(2) a number in round brackets indicates a pause timed to the nearest second

:: $\quad$ a colon indicates lengthening of a sound with additional colons indicating further lengthening

no underlining indicates a word spoken louder than those around it

pres- a dash immediately after an item indicates that the speaker has broken off before completing the utterance

[ square brackets on successive lines indicate the beginning of simultaneous

[ speech

$=\quad$ equals signs indicate that there is no interval between adjacent utterances

\{mhm\} curly brackets enclose brief utterances made during another speaker's turn, which show acknowledgement of what is being said

((sighs)) text in round brackets indicates either contextual information or non-verbal vocalisations

(?guess) text in round brackets preceded by a question mark indicates an educated guess

$\mathrm{hh} / \mathrm{ha}$ indicate units of laughter 
were subsequently asked by letter for written permission to analyse the recording. Ninety-seven per cent of patients $(n=266)$ who were approached agreed initially to have their consultations recorded; of these, written permission was obtained to analyse 101 (70\%) face-to-face consultations and 76 (63\%) telephone consultations. ${ }^{8}$ One hundred and twentythree recordings of consultations (72 telephone and 51 face-to-face) were suitable for conversation analysis. Consultations in which the audio quality was very poor were excluded as were a number of consultations in which part of the recording was missing. All 123 of the remaining recordings were audited and a content log was created for each consultation. A subset of 65 consultations (32 telephone and 33 face-to-face) was then selected for detailed analysis in a purposive sample designed to include, for each channel: one consultation by each GP; examples of both new and follow-up consultations; consultations for different types of problem; consultations both high and low in the number of problems presented; and both the shortest and the longest recorded consultation.

\section{Analytical focus}

It has long been recognised that primary care consultations are carried out through a series of distinctive phases or stages, with communicative structures shaped by the tasks that are performed in them, and this is reflected in medical education and training. ${ }^{11}$ The existence of this structure as a point of reference made the present investigation more straightforward since it was possible to compare communicative practices primarily within stages. Thus, communicative practices leading to problem disclosure were explored mainly within the initiating the session stage, practices used by doctors to obtain additional information about problems in the gathering information stage, and practices resulting in follow-up of problems in the explanation and planning stage..$^{12}$ Because it creates natural transition

\section{Table 1. The different types of consultation.}

\begin{tabular}{lccccccc} 
& \multicolumn{2}{c}{1 concern } & \multicolumn{2}{c}{2 concerns } & \multicolumn{2}{c}{3 concerns } \\
\cline { 2 - 9 } Consultation topic & FtFC $^{\mathrm{a}}$ & $\mathrm{TC}^{\mathrm{a}}$ & FtFC & TC & FtFC & TC & Total \\
\hline New symptoms only & 9 & 12 & - & - & 1 & - & 22 \\
\hline Ongoing treatment & 3 & - & 3 & 4 & 4 & - & 14 \\
\hline $\begin{array}{l}\text { New symptoms and } \\
\text { ongoing treatment }\end{array}$ & - & - & 8 & - & 2 & - & 10 \\
\hline Administrative needs & - & 7 & - & 1 & - & - & 8 \\
\hline Treatment problem & 2 & 9 & - & - & - & - & 11 \\
\hline Total & 14 & 28 & 11 & 5 & 7 & - & 65 \\
\hline
\end{tabular}

${ }^{a}$ FtFC = face-to-face consultation. TC = telephone consultation. points at which the topic is likely to change, the phase-by-phase structure of a typical consultation also facilitated the examination of the methods used by doctors and patients to close discussion of topics. By concentrating on these transition points, it was possible to determine whether transition occurred when topic development appeared to be complete, or whether it took place as a result of curtailment of discussion by either doctor or patient. The researchers also considered whether the discussion of subtopics within phases was curtailed by either doctor or patient.

\section{Procedure}

To identify the communicative practices of doctors and patients, conversation analysis was used, a methodology that reveals the organising principles underlying interaction and, when applied to collections of texts, gives insight into regularities and patterns that are present during the conduct of different social activities. ${ }^{13}$ Conversation analysis is carried out through repeated audit of recordings, supported by detailed transcriptions of the interaction that is captured in them. Consequently, the researchers began by making careful transcriptions of all the consultations selected for indepth analysis, using a simplified version of the Jefferson system which is widely adopted as an adjunct to conversation analysis, ${ }^{14}$ and these transcriptions were subsequently used to support analysis based on the recordings. Transcription conventions are shown in Box 1.

The next step was to analyse the turn-by-turn organisation of the interaction in consultations, paying close attention to practices that facilitated disclosure and discussion of patients' problems and those that inhibited them. While conducting the conversation analysis, the researchers remained attentive to the smallest observable elements of communicative practice, including pauses, silences, and simultaneous speech, as well as grammar, vocabulary, and intonation, making possible a level of comparison between face-toface and telephone consultations that other methods do not afford. See Box 2 for a worked example of this method.

The constant comparative method was used to identify both recurrent patterns of communicative practice and deviant cases, and regular team meetings were held, during which there was orderly and meticulous discussion leading to modification or verification of interim findings. In addition, when the analysis of transcriptions was complete, a random sample of consultations that had not been transcribed was re-audited, in order to check the validity of the study findings. ${ }^{15,16}$ 


\section{Box 2. Illustration of analytical method.}

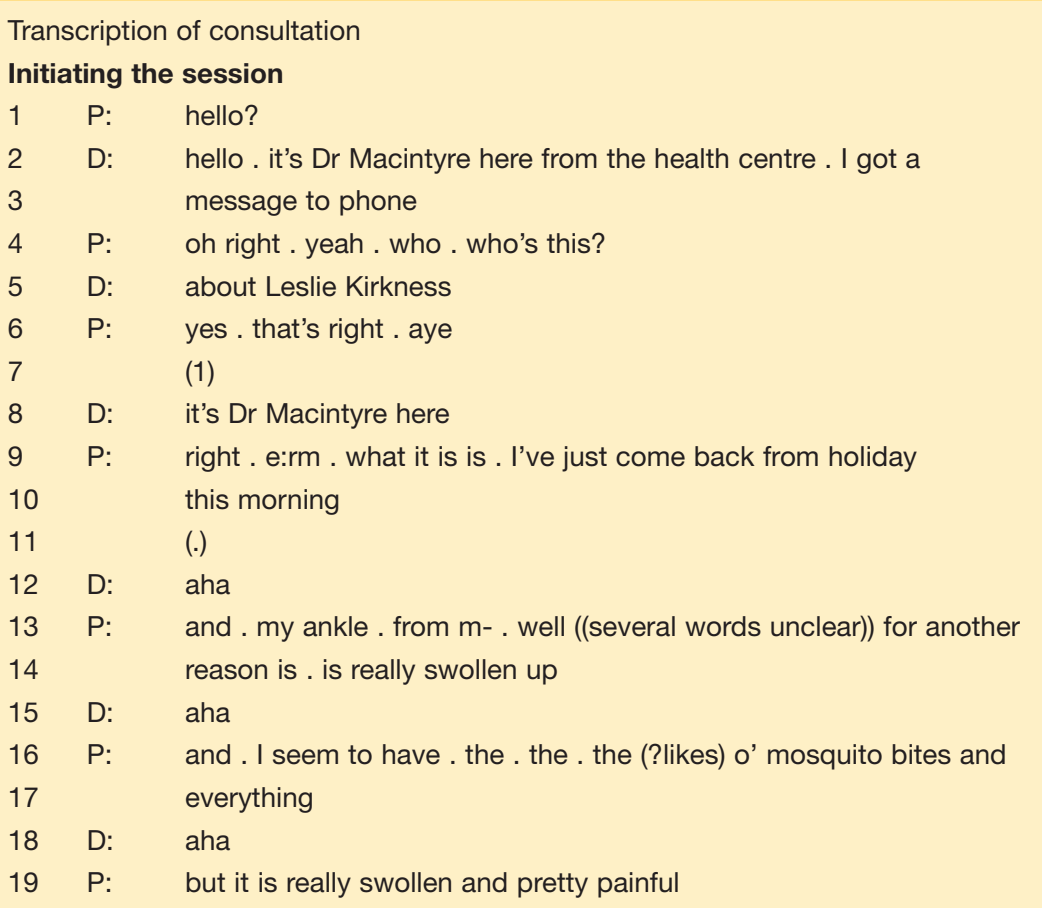

\section{Gathering information}

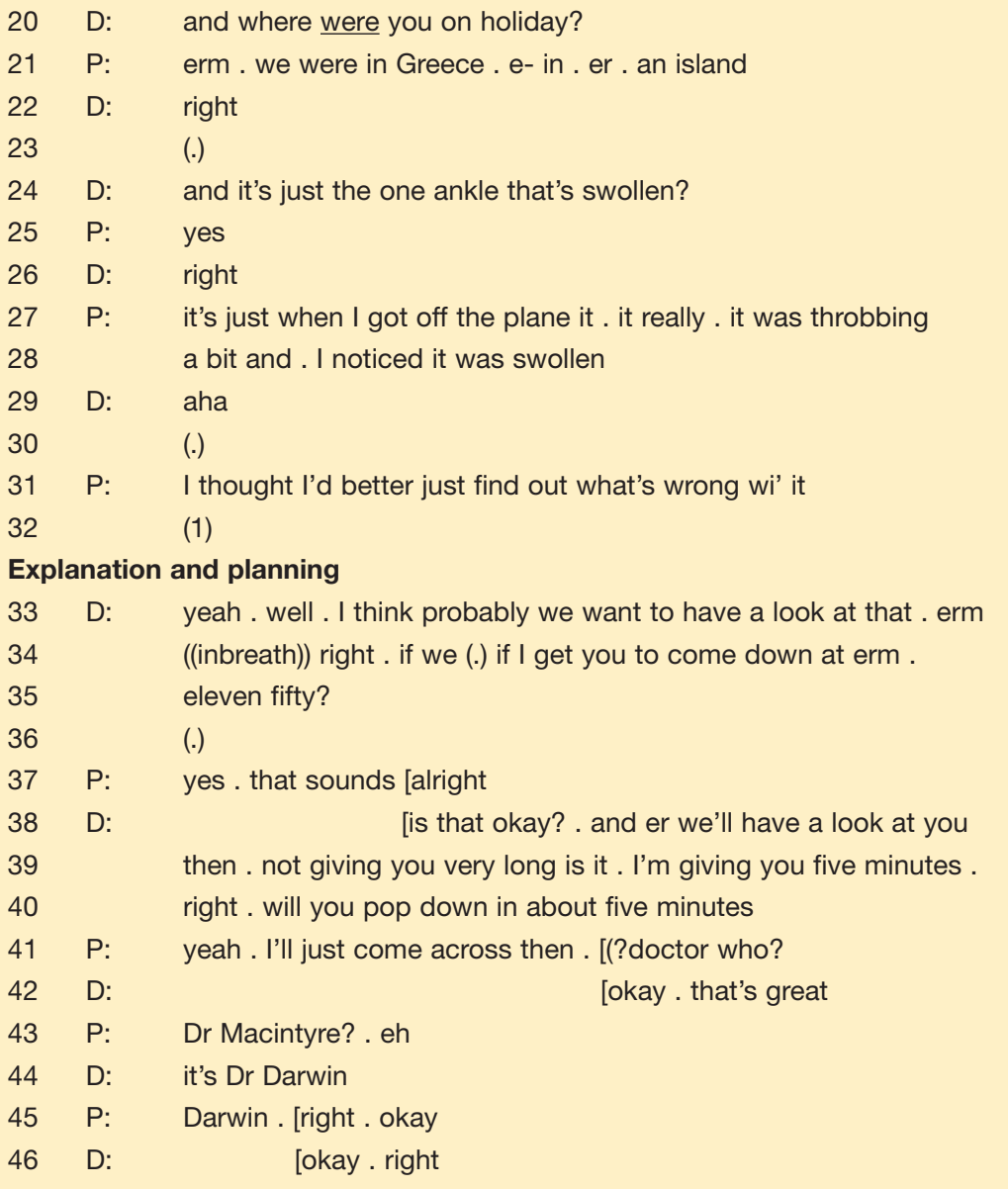

Closing the session

47 P: right . fine . bye

continued ... 


\section{Box 2 continued. Illustration of analytical method.}

The first communicative task for doctor and patient is to find a means of initiating the medical discussion. ${ }^{17}$ In the transcribed example, after the interaction has been launched through an exchange of greetings (lines 1-2), the doctor (D) makes two statements that implicitly suggest that problem disclosure is expected (lines 2-3). One of these is his self-identification as a medical practitioner, the other a reference to the earlier call through which the patient $(P)$ has shown that he wishes to speak to a doctor. However, the patient does not appear to understand that his call to the health centre is being returned (line 4) and there is a breakdown in communication which is revealed by the unusually long one second pause (line 7)..$^{18}$ It is likely that the interruption of the flow of talk arises because the doctor has expected the patient to continue his turn (line 6) with problem disclosure. A clue to this is the doctor's repetition of his selfidentification as a medical practitioner (line 8), which this time results in the immediate disclosure of a concern by the patient. The doctor encourages the disclosure (lines 9-19) by using the type of acknowledgement token which indicates that he is listening and wishes to hear more (lines 12, 15 and 18). ${ }^{19}$ There is no evidence that the disclosure is curtailed, and the transition to problem discussion (line 20) only takes place when the patient has shown that disclosure is complete by repeating and intensifying his account of current symptoms (line 19). ${ }^{20}$

In face-to-face consultations, a doctor can gather additional information about patients' concerns by combining verbal and physical means, ${ }^{21}$ but over the telephone only verbal means are available. Here the doctor chooses to gather additional information by asking two questions (lines 20 and 24). The first of these is a request for new information about the circumstances in which the problem arose, and the second a restricted checking question designed to confirm details of the disclosure. The patient provides two pieces of factual information in response to the first question (line 21) and, in response to the second question, not only confirms the information embedded in the question but also goes on to expand his account of symptoms and the context in which they have been experienced (lines 27-28). When the patient finishes this turn the doctor gives him a further opportunity to develop his account again by using the acknowledgement token 'aha' (line 29), which encourages the current speaker to continue, and also by leaving the floor briefly open (line 30). The patient adds only one more point, a justification of his visit (line 31), and the floor is again left open for one second (line 32). The extent of this pause makes it clear that the patient has nothing further to add and that transition either to further questioning or the explanation and planning stage of the consultation is now a possibility. The doctor takes the latter course, following up on the problem by inviting the patient to attend a face-to-face consultation (lines 33-46) rather than attempting to make a diagnosis over the telephone. After mutual confirmation of the arrangements for this follow-up consultation (lines 45-46), there is an immediate transition to closing (line 47).

Only one concern is raised by the patient in this consultation and the doctor does not enquire about additional concerns after the first presenting problem has been dealt with. In some consultations the absence of such an enquiry could reduce safety but in this case there is evidence that it is appropriate. The use of the phrase 'what it is is' by the patient at the outset of the problem disclosure (line 9) indicates that he only wishes to raise one concern and, even if this were not the case, by arranging a follow-up face-to-face consultation the doctor provides an opportunity for the disclosure of additional concerns later.

\section{Box 3. Question categories.}

\section{Questions used to elicit new information}

Example:

D: $\quad$ and is the e:ye itself red or anything?

(1)

P: $\quad$ e:m.no

D: no

\section{Questions used to check established information}

Example:

D: okay . so I- you- you're not taking ibuprofen now and you've had no chest pains since you . er . stopped the . omeprazole

$P: \quad$ nope

D: fine . particularly those related to new symptoms, treatment problems such as difficulties with medication or persistence of symptoms, and administrative needs such as repeat prescriptions and letters. Table 1 shows how these tendencies are exemplified in the subset of consultations selected for in-depth analysis. In most $(n=17 / 22$ [78\%]) of the selected telephone consultations for new as opposed to continuing symptoms, treatment decisions were not made; instead, after verbal examination, patients were invited to a face-to-face consultation. Only two GPs consulted extensively on the telephone with patients suffering from chronic or long-term conditions.

\section{Introduction of patient concerns}

In both face-to-face and telephone consultations, most patients disclosed their first concerns in response to elicitation by doctors. There were also consultations in both consulting channels in which patients revealed problems themselves before a prompt was given and some telephone consultations in which the first concern was the announcement of test results by doctors (Table 2).

Additional concerns were also discussed in 18 
Table 2. The different ways a first patient concern is introduced.

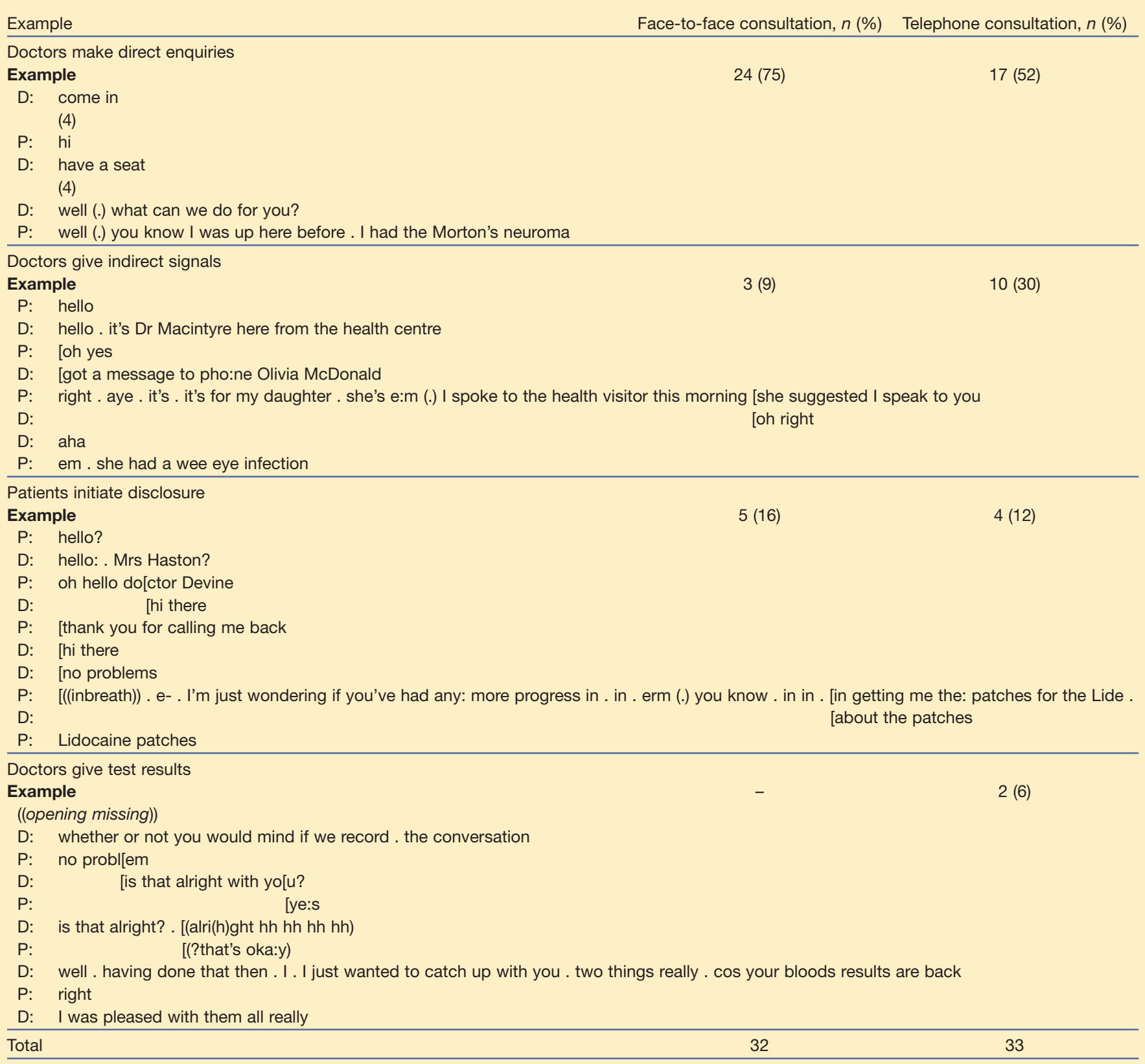

face-to-face and five telephone consultations. In some cases, patients introduced additional concerns in response to further elicitation by doctors but, in both channels, patients were far more likely to present additional concerns without any prompting by a doctor, either by flagging up their intention to present more than one concern during consultation openings or by raising concerns opportunistically after the first presenting problem had been dealt with (Table 3). Doctors directly elicited additional concerns in only 13 consultations, 11 of which (85\%) were face-to-face. Patients responded to this elicitation by discussing additional concerns on 8 of 13 occasions (62\%).

\section{Methods used by doctors to obtain additional information}

Doctors obtained additional information through questioning and, in face-to-face consultations, also by observation. Patterns of questioning were broadly similar in face-to-face and telephone consultations but varied by presenting concern. Question types fell into two broad categories: those designed to elicit new information and those designed to check established information (Box 3).

Questioning in consultations for long-term 


\section{Table 3. The different ways additional concerns are introduced.}

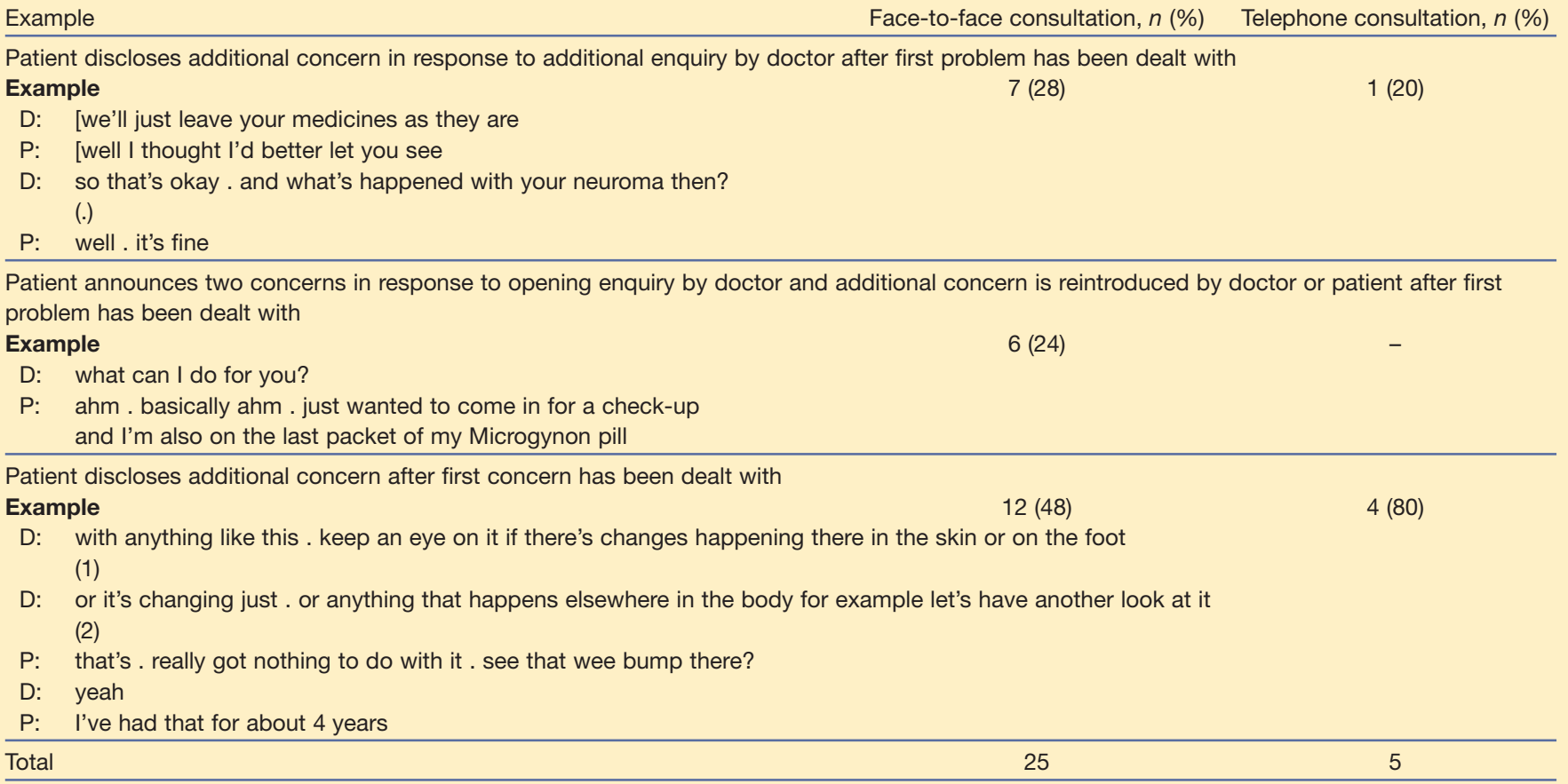

\section{Box 4. Subsidiary topics.}

\section{Health-related matter}

Example:

(Doctor completes examination and the patient explains how leg pain is reducing her independence)

\section{(7)}

P: see I don't like to hang about and and (.) just do nothing . I dinnae like everybody to do anything for me. I like to do wee things for myself \{D: $m h m\}$ like going to the shops and that . but it's getting now that I'm even feared to go to the shops

(2)

D: well I think we'll get some nice . support stockings for you

\section{Small talk}

Example:

(Elderly patient is having a check-up)

D: so what've you got planned at the moment then? . are you?

P: we're home for a bit now . we've just been away in the caravan

D: right . [did you . go to the s-

P: [we were away in May

D: s:outh west was it?

P: tha- . yea- . no the south east . we went to Kent=

D: =south east. right

((continues)) conditions was unsystematic but there were discernible patterns of questioning when new symptoms were disclosed or single continuing treatment problems or administrative needs discussed. In both consulting channels, doctors asked questions designed to elicit new information in response to disclosure of the first new problem by a patient, but when patients consulted about problems that they had diagnosed themselves, doctors asked questions designed to check established information, rather than seek alternative causes. When patients consulted because of continuing treatment problems or administrative needs, doctors tended to ask questions designed to check established information in both face-to-face and telephone consultations. Doctors generally asked similar numbers of questions in face-to-face and telephone consultations in response to the presentation of similar concerns. However, when patients presented self-diagnosed conditions or treatment problems over the telephone, there was less questioning than in face-to-face consultations for similar types of concern. Patients never presented more than two problems in telephone consultations, but when patients presented third or fourth problems in face-to-face consultations doctors asked very few questions.

\section{Follow-up of problems}

The provision of follow-up arrangements and safety- 
Table 4. Safety-net and follow-up arrangements.

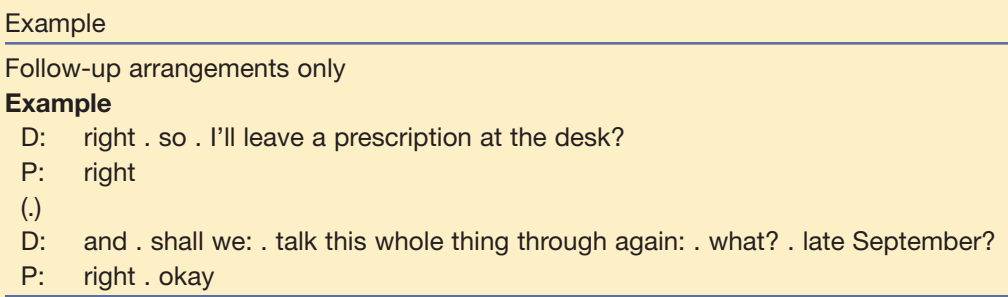

Face-to-face consultation, $n$

Telephone consultation, $n$

Follow-up arrangements and safety-net advice Example

19

16

D: yeah . I mean . th- . th- then I would probably say $y-$. you know . that it . you know . getting a stool sample kind of and probably having a wee look there as well would be worthwhile. just having a feel of her tummy and things like that but . (unclear) very much on how she is in herself and if there's any concerns particularly with . you know . any acute pain

P: yes

D: anything abnormal in the stool . [any blood or mucus or

$P: \quad$ [right

D: anyth[ing like that . and . any . if there's any problems

P: $\quad$ aha

D: with her drinking . you know . any kind of dehydration . obviously you need to get back in touch with us

\section{Safety-net advice}

Example

D: well . we'll just . go with that . I don't think you'll need antibiotics . [eh (unclear)

D: $\quad$ yeah . that would be fine. [I was gonna say see how it is

[alright . should I put Sudocrem on it just to

P:
D: over the next twenty four [or forty eight hours. if you

P: $\quad$ [right

D: think it's recollecting or you think there's more problems with it . then please please please speak. eh . back to me

net advice about how to proceed when problems did not follow an expected course were both at similar levels in face-to-face and telephone consultations. Doctors made follow-up arrangements in $90 \%$ of face-to-face and $78 \%$ of telephone consultations but provided safety-net advice in only $32 \%$ of face-toface and $30 \%$ of telephone consultations. However, safety-net advice was provided in all consultations for new problems in both channels (Table 4).

\section{Closing consultation stages}

Closure of consultation stages was brought about in similar ways in face-to-face and telephone consultations through the use of a small subset of linguistic practices (Table 5). The main component of the initiating the session stage was extended problem disclosure by the patient, usually supported by signals that the doctor was listening. The stage typically ended when patients gave an explicit or an implicit signal that disclosure was complete. In both face-to-face and telephone consultations, patients were more likely to give an explicit signal, such as a restatement of the reason for attending, rather than an implicit one, such as a long period of hesitation or silence, but the tendency was more pronounced in telephone consultations, perhaps because of the unavailability of non-verbal means of communication.
The gathering information stage of consultations closed either when doctors gave a decision related to the presenting concern or when patients restated their reasons for consulting. In face-to-face consultations, this stage was always concluded by doctors but patients also took the initiative and brought about the ending of the stage in $25 \%$ of telephone consultations. Explanation and planning stages in both face-to-face and telephone consultations almost always ended when doctors restated their advice and/or checked that it was acceptable to patients, but in a small number of consultations it was patients who made comments leading to topic closure. The move to close this stage was followed in almost all consultations in both channels by a collaborative sequence through which the consultation was brought to a close. However, there was one telephone consultation in which the patient responded to the doctor's move to close the stage by reopening description of symptoms.

\section{Closing discussion of subtopics through curtailment}

Closure of subtopics through curtailment was infrequent, with only 107 examples in the entire transcribed corpus of almost 100000 words. Both doctors and patients were more likely to cut off topic 


\section{Table 5. Closing consultation stages.}

Closing of reason for attendance stage

(a) Patient initiates closing by restating problem

Example

P: so . em . I just wondered rather than . come in hh em if you could write a prescription for anything?

D: $m$ m yea:h. I'm sure we can . I'm sure we can . w-what sorta what way are they the:y . bothering you. Fiona?

(b) Patient initiates closing by falling silent

Example

D: (inbreath) now . you said there's something else as well?

P: aye

D: aha

P: the- . p- . it's been swelling up

(1)

D: right . is that your left leg? (face-to-face consultation))

Closing of verbal/physical examination stage

(a) Doctor initiates closing by giving decision

Example

P: (patient responds to doctor's question) but . I don't have any problems

D: right . no . well that's fine. well . it's . it's . if you are still . if you're still having a regular . bleed

$\mathrm{P}: \mathrm{mh}[\mathrm{m}$

D: $\quad$ the chances are you are still ovulating so

P: right . [right

D: $\quad$ [you still need protection [(unclear)

(b) Patient initiates closing by restating problem

\section{Example}

Closing of decision-making stage

(a) Doctor initiates closing by repeating advice and checking

Example

D: [I kno:w . but I think . cos the other one's specifically for your skin so ((repeats advice)) see what's going on . but

$P$ : ye:s

$\mathrm{D}:$ is that . is that oka:y?

$P$ : yeah . oh that sounds fine (?doctor)

(b) Patient initiates closing by restating arrangements

\section{Example}

D: yeah . [yes

P: $\quad$ [yeah we had two or three holidays there . it's beautiful . e:rm . so l'll come back and see you a week on Tuesday

D: yes . and we'll. we'll go through the x-ray and [see what it [shows
[right
[see what it impl[ies

development through curtailment in face-to-face consultations, with 89 instances in face-to-face meetings but only 18 in telephone consultations (Table 6). Patients were more likely than doctors to close subtopics in this way and there was no evidence that curtailment by doctors inhibited problem disclosure.

\section{Additional contrasts between communicative practices in face-to-face and telephone consultations}

In telephone consultations, the channel of communication was kept open through interaction that was continuous and orderly with few and short pauses, whereas in face-to-face meetings there were periods of silence when patients were moving in or out of the consulting room or dressing after examination, or doctors were writing-up notes or prescriptions. These interludes provided opportunities for the introduction of additional health-related topics or small talk. In telephone consultations there was less talk than in face-to-face consultations on subsidiary topics, such as health-related matters or small talk (Box 4). These topics were almost always introduced by patients who were being treated for long-term conditions and were less likely to consult by telephone. 


\section{DISCUSSION}

\section{Summary of main findings}

This study shows that there is little difference between the communicative practices used in a sample of face-to-face and telephone consultations in primary care. Telephone consultations are typically shorter and include less presentation and discussion of problems than face-to-face meetings, partly because they are used by patients for discussion of a limited range of single-issue problems, and partly because of intrinsic differences between the two channels of communication. Doctors use similar techniques in face-to-face and telephone consultations to elicit patient concerns and take histories through questioning. Lower levels of questioning in telephone consultations can be attributed to the case-mix rather than to changes in communicative practices. The most interesting aspect of question use in the study sample is its low incidence when patients discuss self-diagnosed or treatment problems over the telephone or raise new concerns opportunistically at the end of face-to-face consultations. There is no evidence that doctors limit disclosure in telephone consultations, although the low levels of elicitation of additional concerns in the telephone channel suggest that they expect consultations to be mono-topical. Patients also contribute to the shorter length of telephone consultations by treating them as mono-topical, by showing more readiness than in face-to-face consultations to initiate problem disclosure without prior elicitation, and by initiating the closure of topics or consultation stages. In addition, in the absence of the opportunities provided by the periods of silence in face-to-face consultations during physical examination and prescription writing, patients consulting by telephone do not introduce additional health-related topics or small talk.

\section{Strengths and limitations of the study}

This is the first study to provide in-depth comparison of communicative practices in face-to-face and telephone consultations. The systematic approach taken to the comparison of similar activities in faceto-face and telephone consultations, and the detailed understanding of interaction between doctors and patients achieved through conversation analysis, sheds new light on the behaviour of doctors and patients in both channels. The absence of visual evidence meant that the researchers were not able to comment on non-verbal communicative practices in face-to-face consultations, nor was any attempt made to relate the study findings to contextual factors such as practice settings (for example, urban or rural) or arrangements for telephone consulting (for example, informal or structured). The sample for

\section{Table 6. Subtopic curtailment.}

\section{Example}

Face-to-face, $n$ Telephone, $n$

\section{Doctor closes subtopic}

Example 39 9

P: $\quad$ and he said ehm (.) 'so what happened this time?' . I says 'somebody was up against my door again' . [I

D:

P: I says 'I I I I can't live like this'

D: no

P: you know I [can't . i- . it

D: [how long has it been going on for?

P: sin- since I moved in

D: which was. how long ago now?

Patient closes subtopic

\section{Example} 50 9

D: the pill won't . e:r . affect that [specifically

P: $\quad$ right

D: so you'll kn[ow in that sense when

$P$ : [okay . so all is . all is . fine at the moment

[then

D: $\quad$ yeah . yeah

P: right

each consultation type was small, the behaviour of doctors and patients may have been affected by their awareness that the interaction was being recorded, and it is also possible that the analysis was influenced by the researchers' own interests and preconceptions. ${ }^{22,23}$ However, the communication patterns found varied consistently by consultation stage and consultation type, confirming that doctors and patients have recognised ways of pursuing specific agendas, ${ }^{9}$ and showing that these are consistent across consulting channels.

\section{Comparison with existing literature}

This study shows that when consulting over the telephone doctors and patients use variants of recognised forms of communicative practice already observed in face-to-face consultations. This is true both of the practices used to elicit and disclose problems, ${ }^{17,24}$ the formats of questions during verbal and physical examination, ${ }^{25}$ and the techniques used to close topics. ${ }^{26}$ In this study, as in previous research, it was found that doctors control the topic agenda in information gathering and explanation and planning stages, and that this is true of both face-toface and telephone consultations. ${ }^{27}$ However, contrary to recent results from outpatient clinics, the present study found that patients as well as doctors do sometimes lead disengagement from topics in both channels. ${ }^{28}$

The study analysis shows that most patients consulting by telephone for new acute symptoms are subsequently seen face-to-face. This confirms the findings of the previous randomised trial ${ }^{8}$ and suggests that such triage for new, acute problems 
may not save time. ${ }^{29}$ Telephone calls tend to be briefer and more focused than face-to-face conversations, particularly in institutional contexts..$^{30}$ However, the small number of examples in the present data of doctors and patients successfully consulting at length by telephone about complex continuing problems, support the researchers' previous finding that it is a medium that could be used more frequently for the care of patients with long-term conditions. ${ }^{31}$ The doctors in the study sample who are consulting by telephone do not elicit additional concerns from patients nor, with a few notable exceptions, do the patients introduce additional problems by making use of recognised communicative strategies such as mention of more than one concern at the beginning of consultations. ${ }^{32}$ This supports the evidence from the recent triangulated focus group study which shows that both doctors and patients consulting by telephone expect to pursue limited agendas. ${ }^{31}$

\section{Implications for future research and clinical practice}

The study findings suggest that, despite continuing concerns about the quality and safety of telephone consulting, a model of service provision in which the telephone is one of the consultation modes offered to patients remains viable. No evidence was found that doctors were more likely to limit disclosure of patients' problems over the telephone than in faceto-face consultations, and questioning and discussion were at comparable levels in face-to-face and telephone consultations for similar presenting concerns. However, there was evidence that doctors carried out only cursory verbal examination when patients consulted by telephone about selfdiagnosed conditions or treatment problems. This sample is small and this would have to be investigated further but these findings are in contrast with training advice to doctors, which particularly emphasises the need to compensate for the absence of visual cues and physical examination in telephone consultations. ${ }^{11}$ The authors believe that both quality and safety would be improved if doctors were made aware that adequate verbal examination is particularly important when the patient is not physically present. They also take the view that doctors should be encouraged to both elicit additional concerns and provide safety-net advice. This should be a matter of routine in both face-toface and telephone consultations but gains added importance in a medium in which the doctor is unable to assess physical symptoms. The researchers were also struck by the lack of questioning when patients presented third or fourth concerns in face-to-face consultations, an omission which appears to confirm anecdotal evidence that the issues raised in the later stages of multi-problem consultations are likely to receive less attention. It is therefore recommend that this tendency be explored further.

\section{Funding body}

The study was funded by a grant from the Chief Scientist Office of the Scottish Government (CZG/2/330).

\section{Ethical approval}

Ethical approval was received from Scottish MREC B Reference Number 05/MRE10/87.

\section{Competing interests}

The authors have stated that there are none.

\section{Acknowledgements}

We would like to thank all the patients and practitioners who took part in the study, the research team and in particular Vicky Hammersley who collected data in our previous study. ${ }^{8}$ We are very grateful to Dr Karen Fairhurst, Dr Hilary Pinnock, Dr Allison Worth and Professor George Freeman for commenting on earlier drafts of this paper.

\section{Discuss this article}

Contribute and read comments about this article on the Discussion Forum: http://www.rcgp.org.uk/bjgp-discuss

\section{REFERENCES}

1. Department of Health. Building on the best: choice, responsiveness and equity in the NHS. London: Department of Health, 2003.

2. Scottish Executive. Our National Health: a plan for action, a plan for change. Edinburgh: NHS Scotland, 2000.

3. Oldham J. Telephone use in primary care. Programme to shape demand has been started in several practices. BMJ 2002; 325(7363): 547.

4. Car J, Sheikh A. Telephone consultations. BMJ 2003; 326(7396): 966-969.

5. Pinnock H, McKenzie L, Price D, Sheikh A. Cost-effectiveness of telephone or surgery asthma reviews: economic analysis of a randomised controlled trial. Br J Gen Pract 2005; 55(511): 119-124.

6. Katz S, Kaltsounis D, Halloran L, Mondor M. Patient safety and telephone medicine. J Gen Intern Med 2008; 23(5): 517-522.

7. Roter D, Larson S. The Roter interaction analysis system (RIAS) utility and flexibility for analysis of medical interactions. Patient Educ Couns 2002; 46(4): 243-251.

8. McKinstry B, Hammersley V, Burton C, et al. The quality, safety and content of telephone and face-to-face consultations: a comparative study. Qual Saf Health Care 2010; (in press).

9. Maynard D, Heritage J. Conversation analysis, doctor-patient interaction and medical communication. Med Educ 2005; 39(4) 428-435.

10. Drew P. Misalignments in 'after-hours' calls to a British GP practice: a study in telephone medicine. In: Heritage J, Maynard D (eds). Communication in medical care: interactions between primary care physicians and patients. Cambridge: Cambridge University Press, 2006: 416-444.

11. Byrne P, Long B. Doctors talking to patients: a study of the verbal behaviour of general practitioners consulting in their surgeries. London: HMSO, 1976.

12. Silverman J, Kurtz S, Draper J. Skills for communicating with patients. 2nd edn. Oxford: Radcliffe Publishing, 2005.

13. Heritage J. Conversation analysis as social theory. In: Turner B (ed). The new Blackwell companion to social theory. Oxford: Blackwell, 2008: 300-320.

14. Maxwell Atkinson MJ, Heritage J. Jefferson's transcript notation. In: Maxwell Atkinson MJ, Heritage J (eds). Structures of social action: studies in conversation analysis. Cambridge: Cambridge University Press, 1984: ix-xiv.

15. Silverman D. Applying the qualitative method to clinical care. In: Daly J, MacDonald I, Willis E (eds). Researching health care: designs, dilemmas, disciplines. London: Tavistock/Routledge, 1992: 176-188. 
16. Miller G. Introduction. Context and method in qualitative research. In: Miller G, Dingwall R (eds). Context and method in qualitative research. London, Thousand Oaks and New Delhi: Sage, 1997: 1-27.

17. Gafaranga J, Britten N. Fire away: the opening sequence in general practice consultations. Fam Pract 2003; 20(3): 242-247.

18. Jefferson G. Notes on a possible metric which provides for 'standard maximum silence' of one second in conversation. In: Roger D, Bull P (eds). Conversation. Clevedon: Multilingual Matters, 1989: 166-196.

19. Schegloff E. Discourse as an interactional achievement: Some uses of 'uh huh' and other things that come between sentences. In: Tannen D (ed). Analyzing discourse: text and talk. Washington: Georgetown University Press, 1982: 71-93.

20. Heritage J, Clayman S. Talk in action: interactions, identities and institutions. Boston, MA: Blackwell, 2010.

21. Boyd E, Heritage J. Taking the patient's medical history: questioning during comprehensive history taking. In: Heritage J, Maynard D (eds). Communication in medical care: interactions between primary care physicians and patients. Cambridge: Cambridge University Press, 2006: 151-184.

22. Labov W. Some principles of linguistic methodology. Language in Society 1972; 1: 97-120.

23. Malterud, K. Qualitative research: standards, challenges and guidelines. Lancet 2001; 358(9280): 483-488.

24. Robinson J, Heritage J. The structure of patients' presenting concerns: the completion relevance of current symptoms. Soc Sci Med 2005; 61(2): 481-493.

25. Robinson J. Closing medical encounters: two physician practices and their implications for the expression of patients' unstated concerns. Soc Sci Med 2001; 53(5): 639-656.

26. Gafaranga J, Britten N. Formulation in general practice consultations. Text 2004; 24(2): 147-170.

27. West C. Routine complications: troubles in talk between doctors and patients. Bloomington, IN: Indiana University Press, 1984

28. Menz F, Al-Roubaie A. Interruptions, status and gender in medical interviews: the harder you brake, the longer it takes. Discourse and Society 2008; 19(5): 645-666.

29. McKinstry B, Walker J, Campbell C, et al. Telephone consultation to manage requests for same-day appointments: a randomised controlled trial in two practices. Br J Gen Pract 2002; 52(477) 306-310

30. Hopper R. Telephone conversations. Bloomington, IN: Indiana University Press, 1992.

31. McKinstry B, Watson P, Pinnock H, et al. Telephone consulting in primary care: a triangulated qualitative study of patients and providers. Br J Gen Pract 2009; 59(563): e209-e218.

32. Campion P, Langdon M. Achieving multiple topic shifts in primary care medical consultations: A conversation analysis study in UK general practice. Sociol Health Illn 2004; 26(1): 81-101. 